\title{
Correction to: The Effect of Corporate Political Activity on MNC Subsidiary Legitimacy: An Institutional Perspective
}

\author{
Shantanu Banerjee ${ }^{1} \cdot$ Sunil Venaik $^{1}$
}

Published online: 3 July 2018

(C) Springer-Verlag GmbH Germany, part of Springer Nature 2018

\section{Correction to: Manag Int Rev}

\subsection{7/s11575-017-0324-0}

The authors have informed the Editorial Office about a typo in the Table 4 referring to the F-Change values in Model 1a where it was mistakenly typed as " $57.94 * * *$ ".

The actual number should be "17.94***". The original analysis and results due to this remain unaffected.

This typo has now been corrected as approved by the Editorial Office of the journal.

Please excuse this mistake.

The original article can be found online at https://doi.org/10.1007/s11575-017-0324-0.

\section{Shantanu Banerjee}

s.banerjee@business.uq.edu.au

1 University of Queensland Business School, Brisbane, Australia 